\title{
A maternally transmitted lethal neonatal progeroid syndrome with prominent genitourinary and gastrointestinal features
}

\author{
Martin B Delatycki, Maureen A Cleary, Agnes Bankier, Peter N McDougall, \\ Jagiit S Ahluwalia, Chung W Chow, Claire M Cooke-Yarborough
}

\section{Victorian Clinical Genetics Service, Murdoch Institute, Flemington Road, Parkville 3052, Victoria, Australia M B Delatycki M A Cleary A Bankier \\ Department of Pathology, Royal Children's Hospital, Flemington Road, Parkville 3052, \\ Victoria, Australia C W Chow \\ C M Cooke-Yarborough}

\section{Department of} Neonatology, Royal Children's Hospital, Flemington Road, Parkville 3052, Victoria, Australia P N McDougall J S Ahluwalia

*Present address: Neonatal Intensive Care Unit, Rosie Maternity Hospital, Robinson Way, Cambridge, UK.

\section{Correspondence to:} Dr Delatycki.

Received 15 October 1996 Revised version accepted for publication 14 January 1997

\begin{abstract}
Twin brothers and their maternal uncle with a previously undescribed neonatal progeroid syndrome are presented. In addition to progeroid features, they had pseudo-obstruction of the urinary and gastrointestinal tracts, severe leucocytosis, liver dysfunction, and low complex III and IV in muscle but not in liver. Previously described neonatal progeroid syndromes and syndromes featuring pseudoobstruction are discussed. The two most likely aetiological mechanisms are an $X$ linked single gene disorder or a mitochondrial disorder. The evidence for these possibilities is presented.

(f Med Genet 1997;34:520-524)
\end{abstract}

Keywords: progeroid; pseudo-obstruction; mitochondria

Twin brothers and their maternal uncle presented with progeroid features and gastrointestinal and urinary tract pseudoobstruction and died in infancy. No specific diagnosis could be made pathologically or by comparison with previously described syndromes.

\section{Case reports}

PATIENT 1

Patient 1 (III.4, fig 1) was born at term to non-consanguineous parents. Weight was $2115 \mathrm{~g}$ (<3rd centile), length $43 \mathrm{~cm}$ ( $<3 \mathrm{rd}$ centile), and occipitofrontal head circumference
II

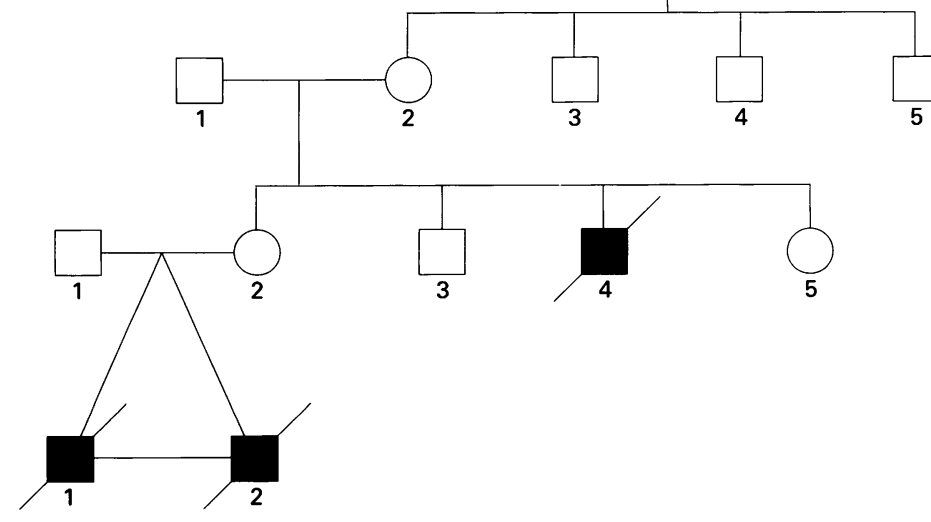

(OFC) $30 \mathrm{~cm}$ (<3rd centile). He was noted to have several dysmorphic features including hirsutism with a low anterior hair line, a small jaw and mouth, flat philtrum, small upturned nose, folded down ears, undescended testes, micropenis, and dorsiflexed halluces. The abdomen was distended and renal ultrasound showed grossly dilated kidneys and ureters. A smal patent ductus arteriosus was present. Crania ultrasound and ophthalmological examination were normal. He had an unexpected cardiorespiratory arrest on day 4 and died. No clinical photographs were taken of this baby. The karyotype was $46, \mathrm{XY}$.

Necropsy showed a markedly hypertrophied bladder with enlarged kidneys and dilated renal pelvis and ureters, but no obstructing lesion in the urethra. The large bowel had focal areas of necrotising enterocolitis. The liver showed marked intracanalicular cholestasis but no obvious obstructive lesion in the biliary tree was identified.

\section{PATIENTS 2 AND 3}

Patients 2 and 3 (IV.1 and IV.2, respectively, in fig 1 , figs 2 and 3 ) were monochorionic monoamniotic twin boys, born to the sister of patient 1. Patient 1's sister and her husband are non-consanguineous and are of different cultural backgrounds. An ultrasound at 36 weeks' gestation showed hydronephrosis in both twins with one having hydroureter bilaterally as well The bladder was reported as normal. Liquor volume was normal. At birth at 37 weeks' gestation, both infants were noted to be growth retarded, dysmorphic, and had early onset respiratory distress requiring ventilation with $100 \%$ oxygen.

Patient 2 had a birth weight of $2300 \mathrm{~g}(<10$ th centile), length of $42.5 \mathrm{~cm}$ ( $<10$ th centile), and OFC of $34.5 \mathrm{~cm}$ (50th centile). Multiple dysmorphic features were present and included prominent parietal bones, hair extending onto the forehead and cheeks, a very small anteverted nose, flat philtrum, micrognathia microstomia, and a markedly distended abdomen. The anterior fontanelle was widely open Formal ophthalmological examination did not show any definite pathology and in particular there were no cataracts.

On day 1 he had a cardiovascular collapse associated with a marked metabolic acidosis (pH 6.77, $\mathrm{pCO}_{2} 67 \mathrm{~mm} \mathrm{Hg}, \mathrm{HCO}_{3} 9.3 \mathrm{mmol} / 1$, base deficit $>22 \mathrm{mmol} / \mathrm{l}$ ). $\mathrm{He}$ responded to supportive measures of intravenous albumin,

Figure 1 Family pedigree. 


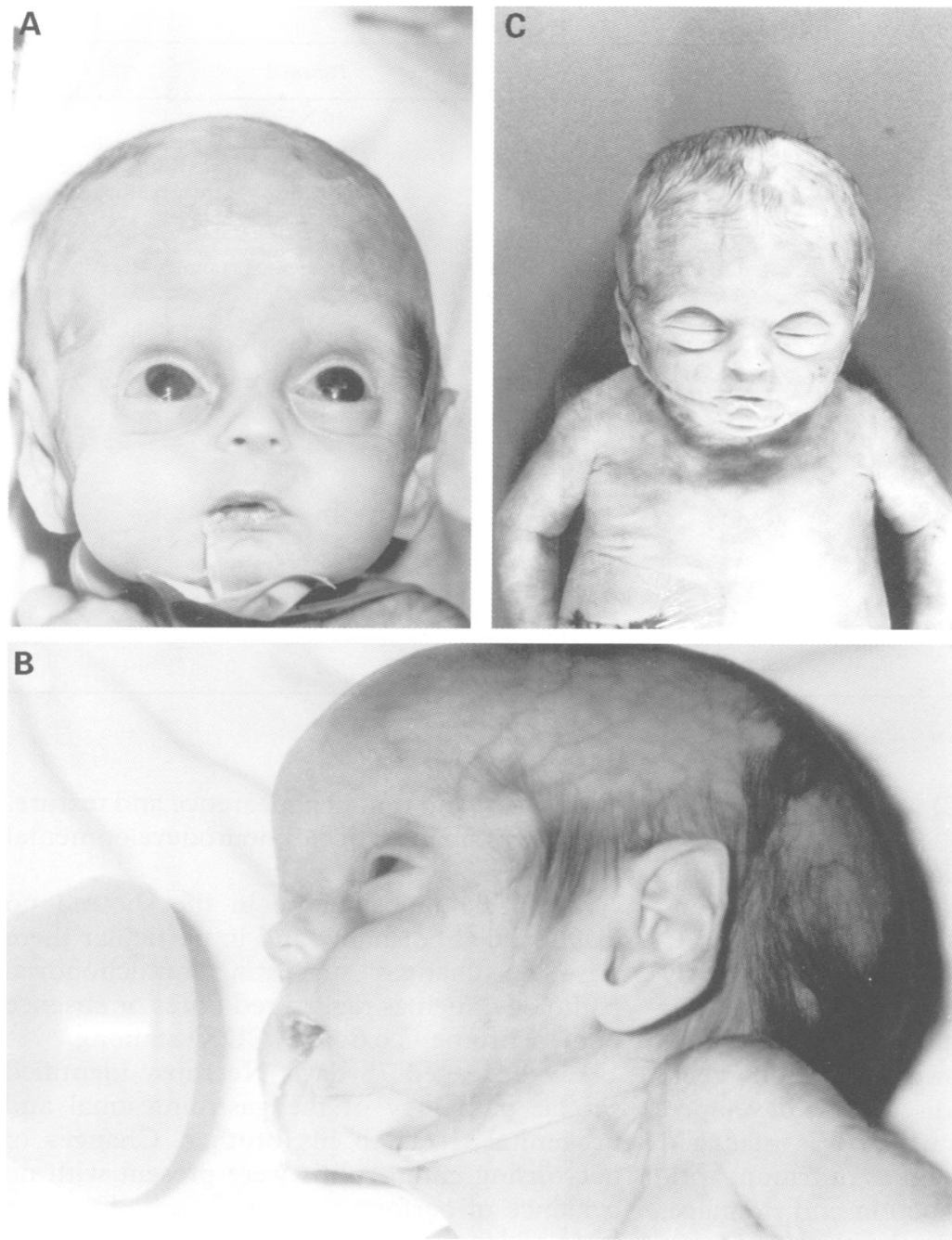

Figure 2 Facial features of patients 2 and 3. (A) Patient 3 at 56 days of age. Note the progeroid appearance with deep eyes, maxillary hypoplasia, hypoplastic nose, small mouth, and relatively large ears. The baby in fact had hair extending onto his forehead, but much of this was shaved off to facilitate intravenous access. (B) Lateral view of patient 3 at 56 days of age. Note deep set eyes and hypoplastic nose. (C) Patient 2 post mortem. Note similar features to his brother but progeroid features less well developed. (Photographs reproduced with permission.)
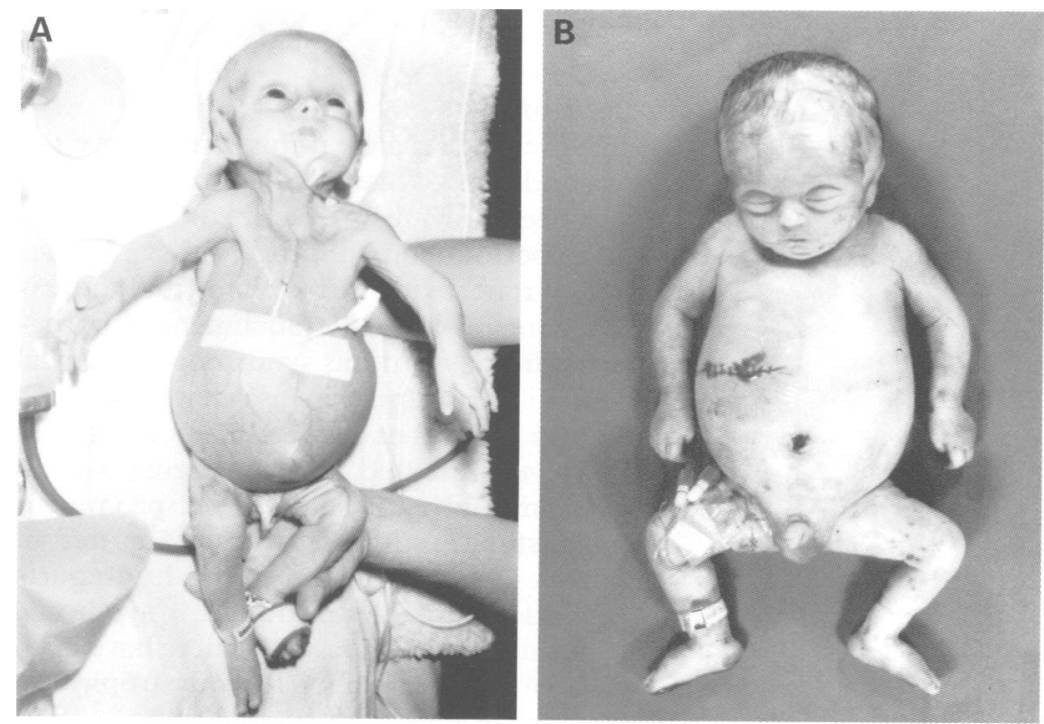

Figure 3 Whole body views of patients 2 and 3. (A) Patient 3 at 56 days of age. Note the grossly distended abdomen with lack of subcutaneous fat with buccal sparing and prominent subcutaneous veins. (B) Patient 2 post mortem. Note similar features to twin but not as well progressed given his earlier age at death. bicarbonate, and a dopamine infusion. Liver function was abnormal with raised transaminases. Urine organic acids showed a high lactate with a milder increase of 4-hydroxyphenyllactic acid and 4-hydroxypyruvic acid. Serum ammonia was initially $364 \mu \mathrm{mol} / 1(\mathrm{~N}<50)$, but returned to normal as liver function improved without specific therapy. Plasma amino acids, very long chain fatty acids, and carnitine were all normal. The abdomen remained grossly distended throughout and he never passed meconium. Abdominal $x$ ray at this time was notable for a gasless bowel except for a single dilated loop interpreted as being consistent with necrotising enterocolitis. Abdominal ultrasound on day 2 of life showed bilateral dilatation of the renal pelvices and ureter and a thickened bladder wall. Micturating cystourethrogram did not show any obstructive lesion. He was clinically unfit for rectal suction biopsy or barium studies of the lower gastrointestinal tract. Echocardiography showed a patent ductus arteriosus. Karyotyping was normal $(46, \mathrm{XY})$. He developed hyperkalaemia secondary to acute renal failure and died on day 12 .

Gross findings at necropsy were distended large bowel and dilated pelvicalyceal systems with marked dilatation of both ureters. The bladder was massively hypertrophied but no distal obstructive lesion was found. Histologically, the lungs showed resolving hyaline membrane disease and bronchopneumonia. The liver showed features of erythrophagocytosis and cholestasis without evidence of hepatitis. There was marked medial hypertrophy of the bladder wall with an increase in fibrous tissue both in the lamina propria and between muscle bundles. The bowel wall was diffusely thinned with an attenuated muscularis. Myenteric ganglion cells were present throughout and of normal appearance. Histological changes consistent with necrotising enterocolitis were found but there was no evidence of perforation or stricture. The brain showed a normal gyral pattern. There was marked softening of the posterior frontal lobes bilaterally with moderate bile staining and ischaemic/anoxic changes were confirmed histologically. Electron microscopy of liver and skeletal muscle was unremarkable and, in particular, the mitochondria looked normal.

Respiratory chain enzymology was performed on muscle and liver obtained within one hour of death using the techniques described in Rahman et al. ${ }^{1}$ Citrate synthase (CS) is used as a marker enzyme of mitochondrial function and results are expressed both as a percentage of control tissue enzyme activity and as a percentage of CS activity. Muscle enzyme studies showed low complex III and IV (26 and $27 \%$ of control respectively, $52 \%$ relative to CS). This result is considered consistent with but not diagnostic of a respiratory chain defect. In contrast, liver enzyme studies showed a normal complex III level $(13.3 / \mathrm{min} / \mathrm{mg}$; normal range 9-14) and a high complex IV level (3.4 $/ \mathrm{min} / \mathrm{mg}$; normal range 1.1-1.6). None of the common mitochondrial DNA mutations (nt 3243 A to G, nt 8344 A to G, nt 8993 T to 
Table 1 Results of investigations on the patients

\begin{tabular}{|c|c|c|c|}
\hline Investigation & Patient 1 & Patient 2 & Patient 3 \\
\hline Karyotype & $46, X Y$ & $46, \mathrm{XY}$ & $46, X Y$ \\
\hline Urine amino acids & nd & Normal & Slightly raised pipecolic acid \\
\hline Urine organic acids & nd & $\begin{array}{l}\text { Raised lactate, } 4 \\
\text { hydroxyphenyllactate, } \\
\text { 4-hydroxypyruvate }\end{array}$ & $\begin{array}{l}\text { Raised 4-hydroxyphenyllactic and } \\
\text { 4-hydroxyphenylpyruvic acids }\end{array}$ \\
\hline Respiratory chain enzymes in liver & nd & Raised complex IV & nd \\
\hline Respiratory chain enzymes in muscle & nd & Decreased complex III, IV & Decreased complex III, IV \\
\hline Total carnitine $(35-65)$ & nd & 43 & 12 \\
\hline Free carnitine $(30-60)$ & nd & 20 & 8 \\
\hline Mitochondrial DNA & nd & No mutation detected & No mutation detected \\
\hline Lactate maximum $\mathrm{mmol} / \mathrm{l}(1.0-1.8)$ & nd & 23.5 & 3.0 \\
\hline Very long chain fatty acids & nd & Normal & Normal \\
\hline Plasma amino acids & nd & Normal & nd \\
\hline \multicolumn{4}{|l|}{ White cell count maximum $10^{9} / 1$} \\
\hline$(4-11)$ & 2.3 & 21.9 & 94.7 \\
\hline AST U/1 (20-80) & nd & 172 & 146 \\
\hline Total protein $\mathrm{g} / 1(50-71)$ & nd & 51 & 83 \\
\hline Albumin $g / 1(29-45)$ & nd & 38 & 43 \\
\hline Bilirubin conjugated $\mu \mathrm{mol} / 1$ & 80 & 167 & 79 \\
\hline \multicolumn{4}{|l|}{ Blood ammonia maximum $\mu \mathrm{mol} / 1$} \\
\hline$(<50)$ & nd & 364 & 41 \\
\hline Triglycerides $\mathrm{mmol} / \mathrm{l}(0.9-2.0)$ & nd & nd & 3.3 \\
\hline Cholesterol mmol/l $(<4.5)$ & nd & nd & 5.4 \\
\hline
\end{tabular}

nd: not done

$\mathrm{G}$, nt $8993 \mathrm{~T}$ to $\mathrm{C}$ ) were present in lymphocytes or muscle.

Patient 3 had an identical appearance to his brother. His birth weight was $2360 \mathrm{~g}$ (5th centile), length $43.5 \mathrm{~cm}$ (<3rd centile), and OFC $34.5 \mathrm{~cm}$ (50th centile). He also had a grossly distended abdomen and a thickened bladder wall was visualised on ultrasonography. A suction rectal biopsy showed ganglion cells, excluding Hirschsprung disease. He developed necrotising enterocolitis which was managed conservatively with intravenous nutrition, antibiotics, and nasogastric suction and drainage. Patient 3's phenotype evolved with time. Over a period of weeks he developed a progeroid appearance with deeply set eyes, prominent cheeks, and relative enlargement of the cranium, and marked reduction of subcutaneous fat with prominent superficial veins was seen throughout including on the buttocks. There were no abnormal fatty deposits. The skin was

Table 2 Comparison of the clinical features in the patients described with those seen in Wiedemann-Rautenstrauch syndrome

\begin{tabular}{|c|c|c|}
\hline Clinical sign & Cases presented & $\begin{array}{l}\text { Wiedemann-Rautenstrauch } \\
\text { syndrome }\end{array}$ \\
\hline Survival & All dead by 75 days & Prolonged survival recorded \\
\hline IUGR & Yes & Yes \\
\hline Postnatal growth retardation & Severe & Yes \\
\hline Neurodevelopmental progress & $\begin{array}{l}\text { None seen in longest } \\
\text { survivor }\end{array}$ & $\begin{array}{l}\text { Developmental delay in most } \\
\text { cases }\end{array}$ \\
\hline Sex & All male & Male and female \\
\hline Pseudohydrocephalus & No & Yes \\
\hline Fontanelles & Wide anterior & Wide anterior, delayed closure \\
\hline Prominent scalp veins & Yes & Yes \\
\hline Hair & Low anterior hair line & Sparse \\
\hline Progeroid face & Yes & Yes \\
\hline Eyes & Deep set & Deep set \\
\hline Nose & Very small & Small, beaked \\
\hline Mouth & Small & Small \\
\hline Natal teeth & No & Yes \\
\hline Jaw & Micrognathia & Prominent \\
\hline Lipoatrophy & Yes & Yes \\
\hline Sacral fat accumulation & No & May occur with time \\
\hline Sudanophilic leucodystrophy & No & Yes \\
\hline \multicolumn{3}{|l|}{ Pseudo-obstruction of GIT, } \\
\hline GUT & Yes & No \\
\hline Liver dysfunction & Yes & No \\
\hline Inheritance & ?X linked, ?mitochondrial & Autosomal recessive \\
\hline
\end{tabular}

IUGR: intrauterine growth retardation, GIT: gastrointestinal tract, GUT: genitourinary tract. translucent and thin in appearence and texture. There was no evidence of neurodevelopmental progress.

A muscle biopsy done in life showed no diagnostic abnormality and in particular there were no changes suggesting mitochondrial pathology, such as ragged red fibres or absence of cytochrome $\mathrm{C}$ oxidase (COX) staining.

He died aged 75 days. Necropsy identified similar pathology of the gastrointestinal and urogenital tracts to his brother. Changes of necrotising enterocolitis were present with no evidence of perforation or stricture. The liver histology was markedly abnormal with cholestatic hepatitis with expanded portal tracts containing a proliferation of bile ductules. Early portal tract to portal tract bridging by fibrous tissue containing proliferated bile ductules was noted. The extrahepatic biliary tree was normal. The neuropathology was essentially normal. Skeletal $x$ rays done post mortem did not show any significant features.

The results of the investigations on the patients are shown in table 1 .

\section{Discussion}

Clearly the three males in this family have the same condition. This association of features has not been previously described.

A number of neonatal progeroid syndromes have been reported. The best known of these is the Wiedemann-Rautenstrauch neonatal progeroid syndrome. ${ }^{2-4}$ In this syndrome the typical progeroid appearance is associated with a prominent jaw and natal teeth. By contrast, the patients we presented had micrognathia and natal teeth were absent. The prominent gastrointestinal and urinary tract features of our cases are not featured in the reports of Wiedemann-Rautenstrauch syndrome which is autosomal recessive. ${ }^{5}$ There have been reports of sudanophilic leucodystrophy in Wiedemann-Rautenstrauch syndrome. ${ }^{67}$ This was not the case in our patients. Table $2 \mathrm{com}$ pares this syndrome with the patients presented. 
Hagadorn $e t a l^{\beta}$ reported a girl with features of a neonatal progeroid syndrome with abdominal distension and vesicoureteric reflux. She differed from the cases we have described in that her gastrointestinal distension resolved with nasogastric feeding and urinary tract dilatation was limited to the renal pelvices. Their patient had hypercalciuria and renal parenchymal calcification. Hypercalciuria was also seen in the patient reported by Bitoun et al but was not looked for in our patients.

The family described by de Martinville et $a l^{10}$ shows some features similar to the cases in this report. Male monozygotic twins with a neonatal progeroid syndrome were presented. An older sib with dysmorphic features died at 50 days. There are no details of the child's sex or clinical features other than talipes equinovarus. The children's mother also had two miscarriages. One twin died at 10 minutes and details are limited regarding its ante- and postmortem features. This child is said to have had the same dysmorphic features as his twin brother which included typical progeroid features as well as micrognathia, sparse hair, eyelashes, and eyebrows, hypoplastic finger nails and absent nails on the fifth finger bilaterally, camptodactyly, and no natal teeth. The longer surviving twin had gastrointestinal problems, the exact nature of which were not reported apart from severe failure to thrive. Significant changes were present in the skin and its appendages. He died at 6 months. Necropsy was not performed. It is possible that these three sibs had the same condition as the patients we describe, but there are some differences between the cases. The patients of de Martinville et $a l^{10}$ had prominent digital changes and there was no description of urinary or gastrointestinal pseudo-obstruction.

The pattern in our family is strongly suggestive of inheritance through the maternal line. Neither a mitochondrial nor an X linked neonatal progeroid syndrome has previously been described.

In view of the prominence of gastrointestinal and genitourinary pseudo-obstruction in our patients, we reviewed other conditions in which such features are mentioned. Intestinal pseudo-obstruction is seen in a number of conditions. Myoneurogastrointestinal encephalopathy syndrome (MNGIE) has pseudo-obstruction as one of its features and in some cases results from mitochondrial DNA deletions. ${ }^{11}$ This condition has not been seen in neonates. An $\mathrm{X}$ linked form of intestinal pseudo-obstruction has recently been mapped to $\mathrm{Xq} 28,{ }^{12}$ but here specific histological abnormalities are present in the bowel. These were not specifically looked for in our cases but there was no pyloric stenosis, malrotation, or short gut. Harris et $a l^{13}$ reported brothers with intestinal pseudo-obstruction and natal teeth who both died before 6 months. No mention of urinary tract dilatation or progeroid features was made and the relevance to our cases is unclear but is of interest given the presence of natal teeth in Wiedemann-Rautenstrauch syndrome.

A mitochondrial aetiology is possible with the maternal inheritance pattern observed in the cases described. The results of mitochon- drial investigations have not given convincing evidence for a mitochondrial cause, however. Although inconsistency in respiratory chain enzyme activities between tissues is often observed in respiratory chain disorders, the abnormal levels are usually observed in the clinically affected organ. In this case, complex III activity was normal in the liver, yet liver function was abnormal, but reduced in muscle, and complex IV was raised in the liver of patient 2. The results cannot be regarded as diagnostic and are at best consistent with primary mitochondrial pathology.

An $\mathrm{X}$ linked recessive aetiology would also be consistent with the inheritance pattern observed. It is possible that a mutation in a gene on the $\mathrm{X}$ chromosome, which encodes for a protein involved in the respiratory chain, is present. None of the subunits encoding respiratory chain enzymes is known to reside on the X chromosome; however, many nuclear encoded genes are yet to be mapped. ${ }^{14}$ Complex III contains 11 polypeptide subunits, 10 of which are nuclear encoded, the other being encoded by a mitochondrial DNA gene. Complex IV is composed of 13 polypeptide subunits of which three are mitochondrially encoded and the remainder nuclear. ${ }^{14}$

An alternative mechanism is that there is a gene locus on the $\mathrm{X}$ chromosome which has an effect on the mitochondrial genome. The first report of linkage for a nuclear gene predisposing to mitochondrial deletions has recently been published. ${ }^{15}$

In conclusion, we have presented a neonatal progeroid syndrome with pseudo-obstruction of the urinary and gastrointestinal tracts affecting monozygous twin boys and their maternal uncle. Their features differ significantly from any cases previously described. These patients add weight to the proposition of Hagadorn et at that there is clinical heterogeneity among conditions diagnosed as a "neonatal progeroid syndrome".

The authors would like to thank Dr David Thorburn for his helpful comments regarding this manuscript and Ms Laurence Dubourg for translating the paper by de Martinville $e t a l^{10}$ into English.

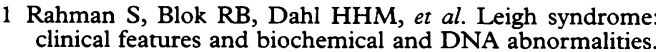
clinical features and biochem

Ann Neurol 1996;39:343-51.
2 Rautenstrauch T, Snigula F, Krieg T, Gay S, Muller PK Progeria: a cell culture study and clinical report of familial incidence. Eur f Pediatr 1977;124:101-11.

3 Wiedemann HR. An unidentified neonatal progeroid syndrome: follow-up report. Eur $\mathcal{F}$ Pediatr 1979;130:65-70. Snigula F, Rautenstrauch R. A new neonatal progeroid syndrome. Eur $\mathcal{F}$ Pediatr 1981;136:325.

5 Devos EA, Leroy JG, Frijns JP, Van den Berghe H. The Wiedemann-Rautenstrauch or neonatal progeroid syndrome: report of a patient with consanguineous parents. Eur ₹ Pediatr 1981;136:245-8.

6 Martin J, Ceuterick CM, Leroy JG, Devos EA, Roelens JG. The Wiedemann-Rautenstrauch or neonatal progeroid syndrome: neuropathological study of a case. Neuropediatrics 1984;15:43-8.

7 Rudin C, Thommen L, Fliegel C, Steinmann B, Bühler U. The neonatal pseudo-hydrocephalic progeroid syndrome (Wiedemann-Rautenstrauch). Report of a new patient and review of the literature. Eur f Pediatr 1988;147:433-88.

8 Hagadorn JI, Wilson WG, Hogge WA, Callicott JH, Beale EF. Neonatal progeroid syndrom

9 Bitoun P, Lachassine E, Sellier N, Sauviun S, Gaudelus J. Bitoun $\mathrm{P}$, Lachassine E, Sellier N, Sauviun S, Gaudelus J.
The Wiedemann-Rautenstrauch neonatal progeroid 
syndrome: a case report and review of the literature. Clin Dysmorphol 1995;4:239-45.

10 de Martinville B, Sorin M, Briard ML, Frézal J. Progeria de Gilford-Hutchinson à début néonatal chez des jumeaux monozygotes. Arch Fr Pediatr 1980;37:679-81.

11 Johns DR, Threlkeld AB, Miller AB, Hurko O. Multiple mitochondrial DNA deletions in myo-neurogastrointestinal encephalopathy syndrome. Am $\mathcal{f}$ Ophthalmol 1993;115:108-9.

12 Auricchio A, Brancolini V, Casari G, et al. The locus for a novel syndromic form of neuronal intestinal pseudoobnovel syndromic form of neuronal intestinal pseudoob-
struction maps to Xq28. Am $₹$ Hum Genet 1996;58:743-8.
13 Harris DJ, Ashcraft KW, Beatty EC, Holder TM, Leonidas JC. Natal teeth, patent ductus arteriosus and intestinal pseudo-obstruction: a lethal syndrome in the newborn. Clin Genet 1976;9:479-82.

14 Shoffner JM, Wallace DC. Oxidative phosphorylation diseases. In: Scriver CR, Beaudet AL, Sly WS, Valle D, eds. The metabolic and molecular bases of inherited disease. 7th ed. New York: McGraw Hill, 1995.

15 Suomalainen A, Kaukonen J, Amati P, et al. An autosomal locus predisposing to deletions of mitochondrial DNA. Nat Genet 1995;9:146-51. 